\title{
Effect of different hydrocolloids on the quality of ketchup during storage
}

\section{Tarun Kumar*, Suresh Chandra, Samsher Singh, Neelash Chauhan and Jaiveer Singh}

\author{
Department of Agricultural Engineering and Food Technology, \\ Sardar Vallabhbhai Patel University of Agriculture \& Technology, Meerut (UP) 250210 India. \\ *E-mail:- tt.king10@gmail.com
}

\begin{abstract}
The study was conducted to investigate the effect of hydrocolloids and storage period on the quality of tomato ketchup. Three hydrocolloids were used for this purpose namely rice starch, corn starch and carageenan @ 0.5 and $1 \%$ respectively. Total seven samples were prepared including a control sample and stored in glass bottles under refrigerator storage condition. It was concluded that ketchup sample containing corn starch @1\% was found to be better than those of prepared with other hydrocolloids incorporation.
\end{abstract}

Keywords: Ketchup, hydrocolloids, corn starch, rice starch, carrageen, storage.

Paper Cited: Kumar, T., Chandra, S., Samsher; Chauhan, N. and Singh, J. (2015). Effect of different hydrocolloids on the quality of ketchup during storage. South Asian J. Food Technol. Environ. 1(2): 152-159.

Tomatoes and tomato products are an important part of human diet. Tomato (Lycopersicon esculentum Mill) is rich source of vitamins A, C, potassium, minerals and fibers. Tomatoes are rich in lycopene, a carotenoid which is important because of its health related properties. The effect of dietary lycopene in reducing the risk of chronic diseases, such as cancer and coronary heart diseases, has already been indicated in epidemiological studies (Giovannucci, 1999; Rao and Agarwal, 1999), but it can be stored for short time in cold storage by chilling or freezing method. For long term preservation, processing is considered to be the best method for the developing countries. There are number of processed products like tomato paste, tomato ketchup, tomato juice, tomato puree, tomato sauce, tomato mat, tomato pickles, powder and others. Among the various tomato products, ketchup is the most important one as it requires limited equipment and the methods used are inexpensive (Alam et al., 2009). Tomato ketchup is a clean, sound product made from properly strained tomatoes with spices, salt, sugar, and vinegar with or without onion and garlic and contains not less than $12 \%$ tomato solids. It is most important and popular condiment consumed extensively and a major part of tomatoes are processed for making tomato ketchup (Sharma and Arora, 2008). According to Saha and Bhattacharya (2010), hydrocolloids are widely used in many food formulations to improve quality attributes and shelf-life. Various types of hydrocolloids used in foods are starch, carrageenan, pectin, gelatin, gum etc.
Sidhu et al., (1997) conducted the study to see the effect of incorporation of different hydrocolloids viz. CMC (carboxymethylcellulose), sodium alginate and gum acacia at $0.75 \%, 1.50 \%$ and $2.25 \%$ level on the consistency of tomato ketchup. The product gave better acceptability at $0.75 \%$ level of addition as compared to higher level due to the product being highly viscous at higher level of incorporation. Gujral et al., (2002) studied effects of hydrocolloids (guar gum, sodium alginate, pectin, CMC (carboxymethylcellulose), xanthan gum and gum acacia) on rheological properties (consistency index and flow value) and serum loss (syneresis) of tomato ketchup during storage at 5 or $50^{\circ} \mathrm{C}$. All hydrocolloids increased consistency of tomato ketchup; however, guar and xanthan gums produced maximum increases followed by $\mathrm{CMC}$, sodium alginate, gum acacia and pectin. With increasing storage duration, consistency of tomato ketchup decreased. The objective of study of Alam et al., (2009) was to evaluate the effect of thickening agents such as carboxymethylcellulose and starch on the quality parameter of tomato ketchup during storage at $30{ }^{\circ} \mathrm{C}$. The moisture content of ketchup was increased by the addition of both the thickening agents. The protein, fibre, ash, acidity and total soluble solid of tomato ketchup were decreased gradually when higher percentage of starch and carboxymethylcellulose were added. Carboxymethylcellulose treated ketchup was found more suitable than the starch treated through sensory evaluation. The effect of two different hydrocolloids on rheological properties and sensory quality of tomato ketchup during storage was studied by 
Desouky and Ibrahim (2014). They added starch to tomato ketchup at level of $0,1,2$ and $3 \%$ while pectin was add at level 0.5 and $1 \%$. Tomato ketchup was stored at room temperature for six months. The rheological behavior of tomato ketchup samples contained different ratios of hydrocolloids were measured in shear rate range 0.0 to $100 \mathrm{~s}^{-1}$ and studied at a wide range of temperatures $\left(5-75^{\circ} \mathrm{C}\right)$ using a Brookfield Digital Viscometer. The results indicated that these tomato ketchups behave as nonNewtonian fluids (pseudo plastic) and have a definite yield stress. Higher significant correlation was found between the viscosity and temperature. The viscosity decreased with increasing in the temperature. All hydrocolloids increased consistency of tomato ketchup. With increasing storage period, viscosity of tomato ketchup decreased. The water separation as important sensory attribute decreased with the addition level of hydrocolloid and increased with increasing storage duration. Sensory tests for tomato ketchups were done during storage and the results indicated that the hydrocolloid addition improved the quality of tomato ketchup in zero time and during storage period.

\section{Materials and Methods}

The experiments were conducted at Food Analysis Laboratory of Sardar Vallabhbhai Patel University of Agriculture and Technology, Meerut (India). Geographically, Modipuram is located in semi-arid and subtropical region at $29^{\circ} 05^{\prime} 19^{\prime \prime}$ North latitude, $77^{\circ} 41^{\prime} 50^{\prime \prime}$ East longitudes and at an altitude of 237 meters above the mean sea level. Fresh, ripe, red in colour tomatoes, free from disease and insects were procured directly from the farmer's village Lawad (Meerut). Tomato variety namely Badshah was used for the present investigation.

\section{Preparation of ketchup}

Ripe tomato fruit were procured from the farmer's field and washed in to fresh water to remove the dust and dirt particles. Tomatoes were placed in to boiling water and cooked for about a minute for removing the skin. Then immediately tomatoes were dipped into a bowl of ice water. This event looses the skin of the tomato which can easily peel out manually. Then the tomatoes were cut in half and squeezed to remove the juice and seeds and cooked in an uncovered stockpot after chopping with onion, garlic, sugar and salt. Meanwhile, remaining spices (mace, cloves, cinnamon, black pepper fruits, and cardamom) were wrapped in cheesecloth and dipped into vinegar in a saucepan and bring to boil. Cover and turned off heat. After holding the tomato mixture for 20 minutes spice bag was discard and combine vinegar and tomato mixture. Boiled about 30 minutes and put boiled mixture through a sieve, returned to pot, boiled gently and stirring frequently, until volume is reduced by one-half. Finally, sodium benzoate (@ $0.25 \mathrm{~g} / \mathrm{kg}$ ) was added as a preservative, and the ketchup was immediately portioned into seven samples of $0.25 \mathrm{~g}$ each. The hydrocolloids (rice starch, corn starch and carageenan @ 0.5\% and 1\% each) were then added into each sample of ketchup considering one as control, at different levels, and stirred for one minute. The final levels of each hydrocolloid by weight in ketchup samples were 0.5 , and $1 \%$. Each ketchup sample was then immediately poured into the glass bottles, while still hot, sealed with screw caps, and then stored at room temperature $\left(30-35{ }^{0} \mathrm{C}\right)$ for $24 \mathrm{~h}$ before the analyses. All the samples were stored for 120 days to determine efficacy of hydrocolloids on physico-chemical and sensory quality of ketchup.

\section{Evaluation of Physico-chemical properties}

Total Soluble Solids (TSS): TSS of tomato ketchup was measured by hand refractometer of range of 0 $32^{\circ}$ Brix recommended by Ranganna (2001).

pH: $\mathrm{pH}$ is the measurement of the logarithm of inverse of hydrogen ion concentration in the solution or $\mathrm{pH}$ is the measurement of $\mathrm{H}^{+}$activity. $\mathrm{pH}$ values were determine using the digital $\mathrm{pH}$ meter, as described by Ranganna (2001).

Acidity: Acidity may be referred as the percent total acid in any food substance. The organic acid is responsible for the sourness of fruit. Acidities of final products were determined using the method as recommended by Ranganna (2001).

Moisture content: Moisture content of samples was determined by hot air oven drying method and calculated using following equation as recommended by AOAC (2000).

Where,

$$
\text { Moisture (\%) }=\frac{\mathrm{W}_{1}-\mathrm{W}_{2}}{\mathrm{~W}_{1}} \times 100
$$

$\mathrm{W}_{1}$ = weight $(\mathrm{g})$ of sample before drying,

$\mathrm{W}_{2}=$ weight $(\mathrm{g})$ of sample after drying,

Optical Density (O.D.): O.D. is the measurement of light intensity that is absorbed by any material when a beam of monochromatic light incident on it. Optical density increase with the browning of product as the brown pigments absorb monochromatic light of particular wavelength. Optical density was determined using digital spectrophotometer.

$\boldsymbol{\beta}$-Carotene: $\beta$-Carotene was determined with the procedure recommended by Srivastava and Kumar (2002), using following equation

$$
\begin{aligned}
& \beta-\text { carotene }\left(\frac{\mu \mathrm{g}}{100 \mathrm{~g}}\right) \\
& =\frac{\text { O. D. } \times 13.9 \times 10^{4}}{\text { weight of sample } \times 560 \times 1000} \times 100
\end{aligned}
$$




\section{Sensory quality of ketchup}

Sensory quality attributes viz. colour, texture, aroma, mouthfeel and overall acceptability of the ketchup samples were evaluated using 9 point hedonic rating test method. This test measures the consumer acceptability.

\section{Packaging and storage}

Glass bottles as packaging material were used and then samples were stored under refrigerator condition.

\section{Results and Discussion}

\section{Physico-chemical properties of ketchup}

The TSS range was observed 24.5 to $26.0{ }^{0} \mathrm{~B}$ for fresh ketchup samples. Higher TSS was observed for ketchup containing corn starch $1 \%$ and carageenan $1 \%\left(26.0{ }^{0} \mathrm{~B}\right)$ while lowest TSS was observed for control sample $\left(24.5{ }^{0} \mathrm{~B}\right)$ just after preparation. After 120 days of storage at refrigerator condition higher TSS was observed for ketchup containing carageenan $1 \%\left(26.0{ }^{0} \mathrm{~B}\right)$. Similar trend were reported by Gujral et al., (2002).

Acidity for fresh ketchup was observed 0.085 to $0.114 \%$ among all the ketchup samples. Higher acidity was observed for ketchup containing corn starch $0.5 \%(0.114 \%)$ just after preparation, while the lowest for ketchup containing corn and rice starch@1\% (0.085\%). Similar trend were reported by Alam et al., (2009).

The $\mathrm{pH}$ for fresh ketchup was found 4.26 to 4.41 among all the ketchup samples. Higher $\mathrm{pH}$ was observed in rice starch $0.5 \%$ (4.41) followed by control, corn starch $0.5 \%$, carageenan $1 \%$, carageenan $0.5 \%$ and corn starch $1 \%$ while lowest for ketchup containing rice starch $1 \%$ (4.26) just after preparation. Decrement in $\mathrm{pH}$ was observed during storage, and after 120 days of storage minimum $\mathrm{pH}$ was found for corn starch and rice starch @ 1\% (4.20).

The optical density for fresh ketchup was observed 0.252 to 0.876 among all the ketchup samples. Maximum optical density was observed for ketchup containing corn starch $1 \%$ while the minimum optical density was found for ketchup containing rice starch $1 \%$ just after preparation. Highest optical density after 120 days was found for ketchup containing corn starch 1\% (0.886).

The beta-carotene range for fresh ketchup was observed 0.830 to $0.845 \mu \mathrm{g} / \mathrm{kg}$ among all the ketchup samples. Higher beta-carotene content was observed for ketchup containing carageenan $0.5 \%$
(0.845) and the lowest for rice starch $0.5 \%(0.830)$ for fresh samples. The beta-carotene decreased with increase in storage period for fresh to 120 days. The moisture content (w.b.) range for fresh ketchup was observed 70 to $81 \%$ among all the ketchup samples.

The moisture content of ketchup was increased by the addition of hydrocolloids and decreased with storage period. Higher moisture content was observed for ketchup containing corn starch $1 \%$ while the lowest moisture content were found for control for fresh samples. The highest moisture content after 120 days of storage at refrigerator condition was found for corn starch $1 \%$. Similar trend was reported by Alam et al., (2009).

\section{Sensory evaluation of ketchup}

The sensory evaluation of ketchup revealed that the highest score for colour was awarded to control and other sample containing $1 \%$ carageenan (8.59, like extremely); however minimum color score was given to sample containing corn starch $0.5 \%$ (8.39, like very much). After 120 days of storage the highest colour score were found for control sample (8.29, like very much). For texture highest score was found for sample containing $1 \%$ carageenan (6.89, like moderately), lowest for sample with corn starch $0.5 \%$ (6.71, like moderately) as a fresh samples. After 120 days of storage the highest texture score was awarded to sample containing carageenan $1 \%$ (6.72, like moderately). Highest score for aroma was rated to the ketchup sample containing $1 \%$ carageenan (8.44, like very much) for fresh samples; however minimum aroma score was found for sample with rice starch of $0.5 \%$ (7.89, like very much). After 120 days of storage highest aroma score was given to sample containing carageenan $1 \%(8.31$, like very much) and minimum to rice starch $0.5 \%$ (7.55, like very much). For change in taste, highest score was designated to corn starch $1 \%$ ( 7.88 , like very much); whereas minimum score for rice starch $1 \%$ (6.51, like moderately) as fresh samples. After 120 days highest taste score was given for sample containing corn starch $1 \%$ (7.62, like very much) and minimum for rice starch $1 \%$ (6.24, like slightly). The highest score for overall acceptability was granted to corn starch $1 \%$ (7.80, like very much) and minimum for corn starch $0.5 \%$ (7.48, like moderately) just after preparation. The overall acceptability of ketchup decreased with increase in storage period. After 120 days highest overall acceptability score were found for sample containing corn starch @ 1\% and sample containing carageenan $1 \%$ and $0.5 \%$ (7.50, like moderately); however lowest value for overall acceptability was found for rice starch $1 \%$ and corn starch $\quad 0.5 \% \quad(7.19, \quad$ like moderately). 
Table 1: Changes in TSS due to hydrocolloids and storage period.

\begin{tabular}{|l|c|c|c|c|c|}
\hline \multirow{2}{*}{ Treatments } & \multicolumn{5}{c|}{ Storage Period (days) } \\
\cline { 2 - 6 } & $\mathbf{0}$ & $\mathbf{3 0}$ & $\mathbf{6 0}$ & $\mathbf{9 0}$ & $\mathbf{1 2 0}$ \\
\hline Control & 24.5 & 24.8 & 25.0 & 25.2 & 25.3 \\
\hline Corn starch $(1.0 \%)$ & 26.0 & 26.3 & 26.3 & 26.4 & 26.5 \\
\hline Corn starch $(0.5 \%)$ & 25.8 & 25.9 & 26.1 & 26.2 & 26.4 \\
\hline Rice starch $(1.0 \%)$ & 25.6 & 25.7 & 25.8 & 25.9 & 26.1 \\
\hline Rice starch $(0.5 \%)$ & 25.4 & 25.5 & 25.7 & 25.8 & 25.9 \\
\hline Carageenan $(1.0 \%)$ & 26.0 & 26.2 & 26.4 & 26.5 & 26.6 \\
\hline Carageenan $(0.5 \%)$ & 25.6 & 25.6 & 25.7 & 25.9 & 26.0 \\
\hline Mean & 25.56 & 25.71 & 25.86 & 25.99 & 26.11 \\
\hline SD & \pm 0.52 & \pm 0.50 & \pm 0.47 & \pm 0.44 & \pm 0.45 \\
\hline CD $5 \%$ & 0.092 & & SE(m) & & 0.031 \\
\hline SE(d) & \multicolumn{2}{|c|}{0.044} & CV & & 0.270 \\
\hline
\end{tabular}

Table 2: Changes in acidity due to hydrocolloids and storage period.

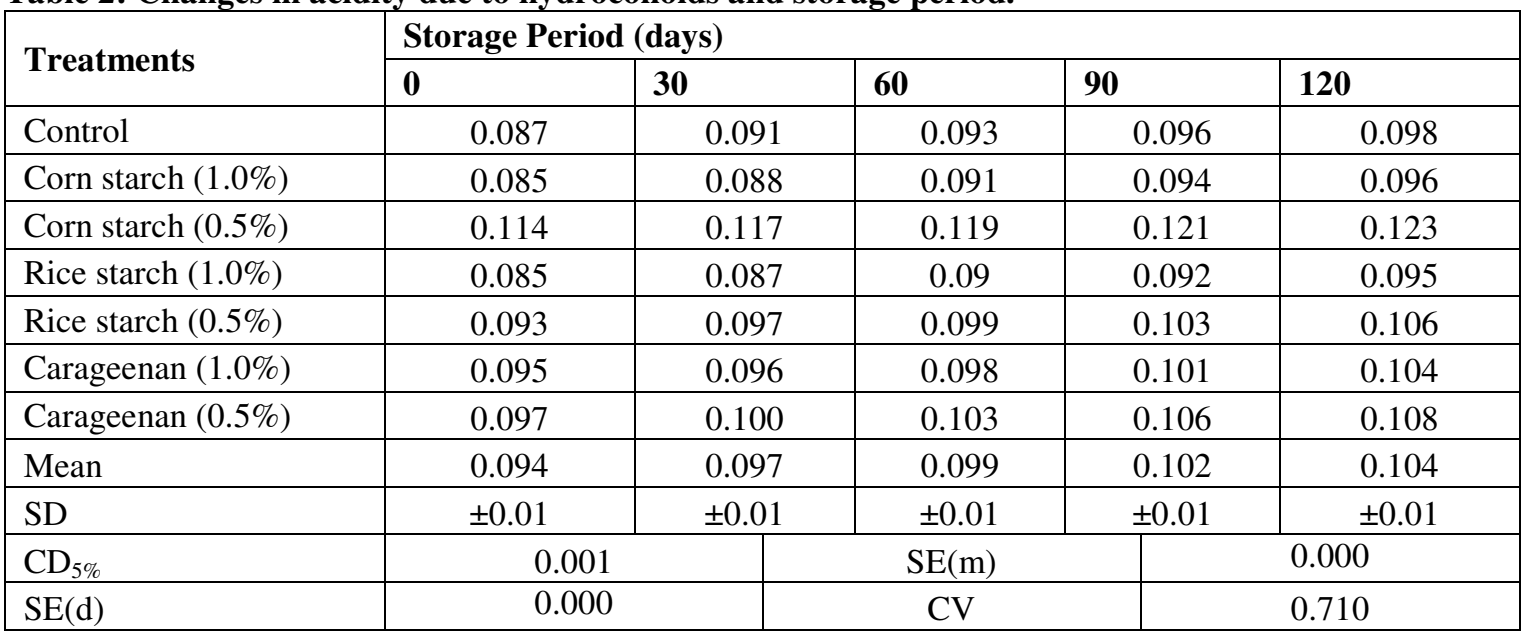

Table 3: Changes in $\mathrm{pH}$ due to hydrocolloids and storage period.

\begin{tabular}{|c|c|c|c|c|c|}
\hline \multirow{2}{*}{ Treatments } & \multicolumn{5}{|c|}{ Storage Period (days) } \\
\hline & $\mathbf{0}$ & 30 & 60 & 90 & 120 \\
\hline Control & 4.38 & 4.37 & 4.36 & 4.34 & 4.32 \\
\hline Corn starch $(1.0 \%)$ & 4.27 & 4.25 & 4.23 & 4.22 & 4.20 \\
\hline Corn starch $(0.5 \%)$ & 4.35 & 4.34 & 4.33 & 4.32 & 4.31 \\
\hline Rice starch $(1.0 \%)$ & 4.26 & 4.24 & 4.22 & 4.21 & 4.20 \\
\hline Rice starch $(0.5 \%)$ & 4.41 & 4.40 & 4.39 & 4.37 & 4.35 \\
\hline Carageenan $(1.0 \%)$ & 4.33 & 4.31 & 4.30 & 4.29 & 4.28 \\
\hline Carageenan $(0.5 \%)$ & 4.30 & 4.29 & 4.28 & 4.26 & 4.25 \\
\hline Mean & 4.33 & 4.31 & 4.30 & 4.29 & 4.27 \\
\hline SD & \pm 0.06 & \pm 0.06 & \pm 0.06 & \pm 0.06 & \pm 0.06 \\
\hline $\mathrm{CD}_{5 \%}$ & \multicolumn{2}{|c|}{0.007} & \multicolumn{2}{|l|}{$\mathrm{SE}(\mathrm{m})$} & 0.002 \\
\hline $\mathrm{SE}(\mathrm{d})$ & \multicolumn{2}{|c|}{0.003} & \multicolumn{2}{|l|}{$\mathrm{CV}$} & 0.120 \\
\hline
\end{tabular}


Table 4: Changes in optical density due to hydrocolloids and storage period.

\begin{tabular}{|c|c|c|c|c|c|}
\hline \multirow{2}{*}{ Treatments } & \multicolumn{5}{|c|}{ Storage Period (days) } \\
\hline & $\mathbf{0}$ & 30 & 60 & 90 & 120 \\
\hline Control & 0.535 & 0.537 & 0.539 & 0.540 & 0.542 \\
\hline Corn starch $(1.0 \%)$ & 0.876 & 0.879 & 0.883 & 0.885 & 0.886 \\
\hline Corn starch $(0.5 \%)$ & 0.480 & 0.490 & 0.510 & 0.520 & 0.530 \\
\hline Rice starch (1.0\%) & 0.252 & 0.256 & 0.259 & 0.261 & 0.262 \\
\hline Rice starch $(0.5 \%)$ & 0.385 & 0.388 & 0.390 & 0.392 & 0.393 \\
\hline Carageenan (1.0\%) & 0.572 & 0.575 & 0.577 & 0.579 & 0.581 \\
\hline Carageenan $(0.5 \%)$ & 0.432 & 0.434 & 0.436 & 0.438 & 0.439 \\
\hline Mean & 0.505 & 0.508 & 0.513 & 0.516 & 0.519 \\
\hline SD & \pm 0.19 & \pm 0.19 & \pm 0.19 & \pm 0.19 & \pm 0.19 \\
\hline $\mathrm{CD}_{5 \%}$ & \multicolumn{2}{|c|}{0.009} & $\mathrm{SE}(\mathrm{m})$ & \multicolumn{2}{|c|}{0.003} \\
\hline $\mathrm{SE}(\mathrm{d})$ & \multicolumn{2}{|c|}{0.004} & $\mathrm{CV}$ & \multicolumn{2}{|c|}{1.287} \\
\hline
\end{tabular}

Table 5: Changes in beta-carotene due to hydrocolloids and storage period.

\begin{tabular}{|c|c|c|c|c|c|}
\hline \multirow{2}{*}{ Treatments } & \multicolumn{5}{|c|}{ Storage Period (days) } \\
\hline & $\mathbf{0}$ & 30 & 60 & 90 & 120 \\
\hline Control & 0.843 & 0.840 & 0.832 & 0.825 & 0.820 \\
\hline Corn starch $(1.0 \%)$ & 0.835 & 0.832 & 0.826 & 0.822 & 0.818 \\
\hline Corn starch $(0.5 \%)$ & 0.844 & 0.840 & 0.831 & 0.827 & 0.821 \\
\hline Rice starch (1.0\%) & 0.838 & 0.834 & 0.830 & 0.825 & 0.821 \\
\hline Rice starch $(0.5 \%)$ & 0.830 & 0.825 & 0.819 & 0.815 & 0.811 \\
\hline Carageenan $(1.0 \%)$ & 0.840 & 0.836 & 0.831 & 0.824 & 0.821 \\
\hline Carageenan $(0.5 \%)$ & 0.845 & 0.842 & 0.837 & 0.833 & 0.829 \\
\hline Mean & 0.839 & 0.836 & 0.829 & 0.824 & 0.820 \\
\hline SD & \pm 0.005 & \pm 0.006 & \pm 0.006 & \pm 0.005 & \pm 0.005 \\
\hline $\mathrm{CD}_{5 \%}$ & \multicolumn{2}{|c|}{0.002} & $\mathrm{SE}(\mathrm{m})$ & \multicolumn{2}{|c|}{0.001} \\
\hline $\mathrm{SE}(\mathrm{d})$ & \multicolumn{2}{|c|}{0.001} & $\mathrm{CV}$ & \multicolumn{2}{|c|}{0.168} \\
\hline
\end{tabular}

Table 6: Changes in moisture content due to hydrocolloids and storage period.

\begin{tabular}{|c|c|c|c|c|c|}
\hline \multirow{2}{*}{ Treatments } & \multicolumn{5}{|c|}{ Storage Period (days) } \\
\hline & $\mathbf{0}$ & 30 & 60 & 90 & 120 \\
\hline Control & 70 & 68 & 67 & 66 & 64 \\
\hline Corn starch $(1.0 \%)$ & 81 & 79 & 78 & 78 & 76 \\
\hline Corn starch $(0.5 \%)$ & 75 & 73 & 72 & 70 & 69 \\
\hline Rice starch $(1.0 \%)$ & 73 & 72 & 71 & 70 & 69 \\
\hline Rice starch $(0.5 \%)$ & 71 & 70 & 69 & 68 & 67 \\
\hline Carageenan $(1.0 \%)$ & 74 & 73 & 73 & 72 & 71 \\
\hline Carageenan $(0.5 \%)$ & 75 & 74 & 73 & 71 & 70 \\
\hline Mean & 74.14 & 72.71 & 71.86 & 70.71 & 69.43 \\
\hline SD & \pm 3.58 & \pm 3.45 & \pm 3.48 & \pm 3.77 & \pm 3.69 \\
\hline $\mathrm{CD}_{5 \%}$ & \multicolumn{2}{|c|}{0.684} & $\mathrm{SE}(\mathrm{m})$ & \multicolumn{2}{|c|}{0.233} \\
\hline $\mathrm{SE}(\mathrm{d})$ & \multicolumn{2}{|c|}{0.330} & $\mathrm{CV}$ & \multicolumn{2}{|c|}{0.726} \\
\hline
\end{tabular}


Table 7: Changes in colour of ketchup due to hydrocolloids and storage period.

\begin{tabular}{|c|c|c|c|c|c|}
\hline \multirow{2}{*}{ Treatments } & \multicolumn{5}{|c|}{ Storage period (days) } \\
\hline & $\mathbf{0}$ & 30 & 60 & 90 & 120 \\
\hline Control & 8.58 & 8.51 & 8.45 & 8.38 & 8.29 \\
\hline Corn starch (1\%) & 8.48 & 8.32 & 8.24 & 8.18 & 8.11 \\
\hline Corn starch $(0.5 \%)$ & 8.39 & 8.31 & 8.24 & 8.17 & 8.09 \\
\hline Rice starch (1\%) & 8.49 & 8.42 & 8.33 & 8.24 & 8.18 \\
\hline Rice starch $(0.5 \%)$ & 8.41 & 8.33 & 8.24 & 8.16 & 8.09 \\
\hline Carageenan (1\%) & 8.59 & 8.53 & 8.45 & 8.38 & 8.28 \\
\hline Carageenan $(0.5 \%)$ & 8.51 & 8.42 & 8.36 & 8.29 & 8.21 \\
\hline Mean & 8.49 & 8.41 & 8.33 & 8.26 & 8.18 \\
\hline SD & \pm 0.08 & \pm 0.09 & \pm 0.09 & \pm 0.10 & \pm 0.09 \\
\hline $\mathrm{CD}_{5 \%}$ & \multicolumn{2}{|c|}{0.022} & \multicolumn{2}{|l|}{$\mathrm{SE}(\mathrm{m})$} & 0.007 \\
\hline $\mathrm{SE}(\mathrm{d})$ & \multicolumn{2}{|c|}{0.011} & \multicolumn{2}{|l|}{$\mathrm{CV}$} & 0.199 \\
\hline
\end{tabular}

Table 8: Changes in texture of ketchup due to hydrocolloids and storage period.

\begin{tabular}{|l|c|c|c|c|c|}
\hline \multirow{2}{*}{ Treatments } & \multicolumn{5}{|c|}{ Storage period (days) } \\
\cline { 2 - 6 } & $\mathbf{0}$ & $\mathbf{3 0}$ & $\mathbf{6 0}$ & $\mathbf{9 0}$ & $\mathbf{1 2 0}$ \\
\hline Control & 6.78 & 6.71 & 6.62 & 6.51 & 6.41 \\
\hline Corn starch (1\%) & 6.72 & 6.68 & 6.60 & 6.52 & 6.46 \\
\hline Corn starch (0.5\%) & 6.71 & 6.67 & 6.61 & 6.53 & 6.44 \\
\hline Rice starch (1\%) & 6.88 & 6.80 & 6.81 & 6.72 & 6.51 \\
\hline Rice starch (0.5\%) & 6.72 & 6.61 & 6.55 & 6.48 & 6.41 \\
\hline Carageenan (1\%) & 6.89 & 6.86 & 6.81 & 6.77 & 6.72 \\
\hline Carageenan $(0.5 \%)$ & 6.81 & 6.76 & 6.69 & 6.62 & 6.56 \\
\hline Mean & 6.79 & 6.73 & 6.67 & 6.59 & 6.50 \\
\hline $\mathrm{SD}$ & \pm 0.08 & \pm 0.09 & \pm 0.10 & \pm 0.11 & \pm 0.11 \\
\hline $\mathrm{CD}$ & 0.045 & & $\mathrm{SE}(\mathrm{m})$ & & 0.015 \\
\hline $\mathrm{SE}(\mathrm{d})$ & 0.022 & $\mathrm{CV}$ & & 0.518 \\
\hline
\end{tabular}

Table 9: Changes in aroma of ketchup due to hydrocolloids and storage period.

\begin{tabular}{|l|c|c|c|c|c|}
\hline \multirow{2}{*}{ Treatments } & \multicolumn{5}{|c|}{ Storage period (days) } \\
\cline { 2 - 6 } & $\mathbf{0}$ & $\mathbf{3 0}$ & $\mathbf{6 0}$ & $\mathbf{9 0}$ & $\mathbf{1 2 0}$ \\
\hline Control & 8.12 & 8.01 & 7.92 & 7.83 & 7.76 \\
\hline Corn starch (1\%) & 8.11 & 8.02 & 7.96 & 7.89 & 7.81 \\
\hline Corn starch (0.5\%) & 8.02 & 7.94 & 7.88 & 7.81 & 7.73 \\
\hline Rice starch (1\%) & 8.08 & 8.01 & 7.96 & 7.88 & 7.81 \\
\hline Rice starch (0.5\%) & 7.89 & 7.81 & 7.72 & 7.63 & 7.55 \\
\hline Carageenan (1\%) & 8.44 & 8.43 & 8.38 & 8.37 & 8.31 \\
\hline Carageenan (0.5\%) & 8.11 & 8.10 & 8.03 & 7.95 & 7.81 \\
\hline Mean & 8.11 & 8.05 & 7.98 & 7.91 & 7.83 \\
\hline SD & \pm 0.17 & \pm 0.19 & \pm 0.20 & \pm 0.23 & \pm 0.23 \\
\hline CD $5 \%$ & 0.045 & & SE $(m)$ & & 0.015 \\
\hline SE(d) & \multicolumn{2}{|c|}{0.021} & CV & & 0.425 \\
\hline
\end{tabular}


Table 10: Changes in taste of ketchup due to hydrocolloids and storage period.

\begin{tabular}{|l|c|c|c|c|c|}
\hline \multirow{2}{*}{ Treatments } & \multicolumn{5}{|c|}{ Storage period (days) } \\
\cline { 2 - 6 } & $\mathbf{0}$ & $\mathbf{3 0}$ & $\mathbf{6 0}$ & $\mathbf{9 0}$ & $\mathbf{1 2 0}$ \\
\hline Control & 7.08 & 6.99 & 6.92 & 6.84 & 6.75 \\
\hline Corn starch (1\%) & 7.88 & 7.82 & 7.78 & 7.71 & 7.62 \\
\hline Corn starch (0.5\%) & 6.79 & 6.71 & 6.68 & 6.59 & 6.51 \\
\hline Rice starch (1\%) & 6.51 & 6.49 & 6.41 & 6.33 & 6.24 \\
\hline Rice starch (0.5\%) & 7.48 & 7.41 & 7.33 & 7.23 & 7.14 \\
\hline Carageenan (1\%) & 6.88 & 6.81 & 6.76 & 6.67 & 6.60 \\
\hline Carageenan (0.5\%) & 7.69 & 7.61 & 7.52 & 7.46 & 7.38 \\
\hline Mean & 7.19 & 7.12 & 7.06 & 6.98 & 6.90 \\
\hline SD & \pm 0.51 & \pm 0.50 & \pm 0.50 & \pm 0.50 & \pm 0.50 \\
\hline $\mathrm{CD}_{5 \%}$ & 0.027 & & $\mathrm{SE}(\mathrm{m})$ & & 0.009 \\
\hline $\mathrm{SE}(\mathrm{d})$ & \multicolumn{7}{|c|}{0.013} & $\mathrm{CV}$ & & 0.296 \\
\hline
\end{tabular}

Table 11: Changes in overall acceptability of ketchup due to hydrocolloids and storage period.

\begin{tabular}{|c|c|c|c|c|c|}
\hline \multirow{2}{*}{ Treatments } & \multicolumn{5}{|c|}{ Storage period (days) } \\
\hline & $\mathbf{0}$ & 30 & 60 & 90 & 120 \\
\hline Control & 7.64 & 7.56 & 7.48 & 7.39 & 7.30 \\
\hline Corn starch (1\%) & 7.80 & 7.71 & 7.65 & 7.58 & 7.50 \\
\hline Corn starch $(0.5 \%)$ & 7.48 & 7.41 & 7.35 & 7.28 & 7.19 \\
\hline Rice starch (1\%) & 7.49 & 7.43 & 7.38 & 7.29 & 7.19 \\
\hline Rice starch $(0.5 \%)$ & 7.63 & 7.54 & 7.46 & 7.38 & 7.30 \\
\hline Carageenan (1\%) & 7.70 & 7.66 & 7.60 & 7.55 & 7.48 \\
\hline Carageenan $(0.5 \%)$ & 7.78 & 7.72 & 7.65 & 7.58 & 7.49 \\
\hline Mean & 7.64 & 7.57 & 7.51 & 7.43 & 7.35 \\
\hline SD & \pm 0.13 & \pm 0.13 & \pm 0.12 & \pm 0.13 & \pm 0.14 \\
\hline $\mathrm{CD}_{5 \%}$ & \multicolumn{2}{|c|}{0.023} & $\mathrm{SE}(\mathrm{m})$ & \multicolumn{2}{|c|}{0.008} \\
\hline SE(d) & \multicolumn{2}{|c|}{0.011} & $\mathrm{CV}$ & \multicolumn{2}{|c|}{0.237} \\
\hline
\end{tabular}

\section{Conclusion}

The results revealed that TSS, acidity and optical density (OD) increased while $\mathrm{pH}$, betacarotene content and moisture content decreased with the increase in storage period. Highest overall acceptability score were found for sample containing corn starch @1\% and another sample containing carageenan $1 \%$ and $0.5 \%$ ( 7.50, like moderately). On the basis of overall sensorial acceptability it can be say that after 120 days, tomato ketchup containing corn starch $(1 \%)$ is most acceptable among them. Ketchup using individually hydrocolloids like rice starch and carageenan @ 0.5\% are more acceptable than $1 \%$, after 120 days of storage.

\section{References}

1. Alam, M.K., Akter, M.A., Nurul Islam, M.S. and Eun, J.B. (2009). Effect of carboxymethyl- cellulose and starch as thickening agents on the quality of tomato ketchup. Pak J Nutrition. 8(8): 1144-1149.

2. AOAC, (2000). Official methods of analysis of AOAC International (17 $7^{\text {th }}$ ed.). Gaitherburg. USA: AOAC International Inc.

3. Desouky, A.E.H. and Ibrahim, A. (2014). Effect of hydrocolloids addition on rheological properties, and sensory quality of tomato ketchup during storage. Benha University publications, Egypt.

4. Giovannucci, E. (1999). Tomatoes, tomato-based products, lycopene, and cancer: Review of the epidemiologic literature. J National Cancer Institute. 91(4): 317-331.

5. Gujral, S.H., Sharma, A. and Singh, N. (2002). Effect of hydrocolloids, storage temperature, and duration on the consistency of tomato ketchup. Intern J Food Properties. 5(1): 179-191. 
6. Ranganna, S. (2001). Handbook of analysis and quality control of fruits and vegetable products. Tata McGraw Hill New Delhi.

7. Rao, A.V. and Agarwal, S. (1999). Role of lycopene as antioxidant carotenoid in the prevention of chronic diseases: A review. Nutrition Res, 19(2): 305-323.

8. Saha, D. and Bhattacharya, S. (2010). Hydrocolloids as thickening and gelling agents in food: a critical review. J Food Sci Tech. 47(6): 587-597.
9. Sharma, M. and Arora, S. K. (2008). Evaluation of tomato cultivars for preparation of commercial tomato products - A review. Bev Food World. 35(5): 30-33.

10. Srivastava, R.P. and Kumar, S. (2002). Fruit and vegetable preservation (principle and practice), $3^{\text {rd }}$ ed. International Book Distributing co. Lucknow.

11. Sidhu, J.S., Bawa, A.S. and Singh, N. (1997). Studies on the effect of hydrocolloids on the consistency of tomato ketchup. J Food Sci Technol. 34(5): 423- 424. 